Respiration 2013;86:439

DOI: $10.1159 / 000355085$

\section{EBUS-TBNA with ROSE-Tinted Spectacles?}

G. Hardavella $a^{a, b}$ N. Navani $i^{a, b}$

a Department of Thoracic Medicine, University College London Hospitals, and ${ }^{b}$ Lungs for Living Research Centre, University College London, London, UK

We read with great interest the recent article by Oki et al. [1]. The authors are to be congratulated on completing a randomised trial of endobronchial ultrasound-guided transbronchial needle aspiration (EBUS-TBNA) with and without rapid on-site cytologic evaluation (ROSE) of samples. They report that ROSE during EBUS-TBNA in the initial diagnosis of lung cancer can reduce the number of punctures per site, affect the number of sampled sites and eliminate the need for additional bronchoscopic procedures. We have some reservations regarding these conclusions.

Cancer medicine has now entered an era of personalisation and it is critical that samples obtained at EBUS-TBNA should be able to phenotype and genotype lung tumours to allow optimum management of patients with advanced non-small cell lung cancer.

Several lines of evidence demonstrate that the use of immunohistochemistry on EBUS-TBNA samples reduces the rate of unclassified non-small cell lung cancer as compared to cytological diagnosis alone [2, 3]. Routine samples from EBUS-TBNA without ROSE are sufficient to allow epidermal growth factor receptor mutation testing in $90 \%$ of patients with adenocarcinoma [2]. In addition, EBUS-TBNA safely provides adequate samples for immunohistochemistry and fluorescence in situ hybridization (FISH) for the detection of anaplastic lymphoma kinase (ALK) fusion genes, thus providing invaluable information for targeted therapy $[4,5]$.

Therefore, we would not recommend stopping sampling simply with a malignant diagnosis at ROSE. The prevention of further passes being made may be a false economy if the sample taken is not suitable for phenotyping and genotyping. Furthermore, ROSE does not seem to be cost-effective in sampling environments in which the per-pass adequacy is high. The effect of ROSE relies strongly on the number of sampling passes and on the accuracy of the assessor [6]. In addition Joseph et al. [7] have recently reported that even in cases where tissue sampling was assessed by ROSE as inadequate, a final diagnosis was made in most patients, thus potentially avoiding additional procedures to prove mediastinal disease.

Evidence shows that ROSE does not increase the diagnostic yield of even conventional TBNA as reported by Trisolini et al. [8]. They conducted a randomised controlled trial to evaluate the extent to which ROSE can be valuable in patients with hilar/mediastinal lymphadenopathy undergoing TBNA. They also reported that ROSE was not associated with any significant diagnostic advantage (even in a subgroup analysis by most prevalent pathologic diagnoses, by lymph node size, by lymph node location and by operator), and it did not affect the percentage of adequate specimens [8].
We also note that Oki et al. [1] reported that the negative predictive value was $40 \%$ in the ROSE group and $63 \%$ in the nonROSE group. One may expect ROSE to improve negative predictive value and make a negative diagnosis more reliable; however, this seems not to be the case and merits further discussion. The number of passes before a node is classified as negative by ROSE requires clarification.

The authors state that ROSE was performed by a cytotechnologist present in the endoscopy suite. We would like to draw attention to that as the routine presence of a cytotechnologist or pathologist in the endoscopy room would significantly increase the cost of an EBUS-TBNA procedure, while there is lack of available efficacy data in meaningful endpoints such as the sensitivity, safety or utility of samples for advanced diagnostics.

\section{Financial Disclosure and Conflicts of Interest}

N.N. is in part supported by the UK National Institute for Health Research University College London Hospitals Biomedical Research Centre.

\section{References}

1 Oki M, Saka H, Kitagawa C, Kogure Y, Murata N, Adachi T, Ando M: Rapid on-site cytologic evaluation during endobronchial ultrasoundguided transbronchial needle aspiration for diagnosing lung cancer: a randomized study. Respiration 2013;85:486-492.

2 Navani N, Brown JM, Nankivell M, Woolhouse I, Harrison RN, Jeebun V, Munavvar M, Ng BJ, Rassl DM, Falzon M, Kocjan G, Rintoul RC, Nicholson AG, Janes SM: Suitability of endobronchial ultrasound-guided transbronchial needle aspiration specimens for subtyping and genotyping of non-small cell lung cancer: a multicenter study of 774 patients. Am J Respir Crit Care Med 2012;185:1316-1322.

3 Ou SH, Zell JA: Carcinoma NOS is a common histologic diagnosis and is increasing in proportion among non-small cell lung cancer histologies. J Thorac Oncol 2009;4:1202-1211.

-4 Kimura H, Nakajima T, Takeuchi K, Soda M, Mano H, Iizasa T, Matsui Y, Yoshino M, Shingyoji M, Itakura M, Itami M, Ikebe D, Yokoi S, Kageyama H, Ohira M, Nakagawara A: ALK fusion gene positive lung cancer and 3 cases treated with an inhibitor for ALK kinase activity. Lung Cancer 2012;75:66-72.

5 Neat MJ, Foot NJ, Hicks A, Breen R, Wilkins B, McLean E, Santis G: ALK rearrangements in EBUS-derived transbronchial needle aspiration cytology in lung cancer. Cytopathology 2013, E-pub ahead of print.

6 Schmidt RL, Howard K, Hall BJ, Layfield LJ: The comparative effectiveness of fine-needle aspiration cytology sampling policies: a simulation study. Am J Clin Pathol 2012;138:823-830.

7 Joseph M, Jones T, Lutterbie Y, Maygarden SJ, Feins RH, Haithcock BE, Veeramachaneni NK: Rapid on-site pathologic evaluation does not increase the efficacy of endobronchial ultrasonographic biopsy for mediastinal staging. Ann Thorac Surg 2013;96:403-410.

$\checkmark 8$ Trisolini R, Cancellieri A, Tinelli C, Paioli D, Scudeller L, Casadei GP, Parri SF, Livi V, Bondi A, Boaron M, Patelli M: Rapid on-site evaluation of transbronchial aspirates in the diagnosis of hilar and mediastinal adenopathy: a randomized trial. Chest 2011;139:395-401.

\section{KARGER}

E-Mail karger@karger.com

www.karger.com/res
2013 S. Karger AG, Basel

0025-7931/13/0865-0439\$38.00/0
Georgia Hardavella

University College Hospital

250 Euston Road, Fourth Floor East

London NW1 2PG (UK)

E-Mail g.hardavella@ucl.ac.uk 